\title{
The genetic relationship of body weight and early-lactation health disorders in two experimental herds
}

\author{
E. Frigo, ${ }^{* 1}$ C. D. Dechow, $†$ O. Pedron, ${ }^{\star}$ and B. G. Cassellł \\ *Department of Veterinary Sciences and Technologies for Food Safety, University of Milan, Via Celoria 10, 20133 Milano, Italy \\ †Department of Dairy and Animal Science, The Pennsylvania State University, University Park 16802 \\ łDepartment of Dairy Science, Virginia Polytechnic Institute and State University, Blacksburg 24061
}

\section{ABSTRACT}

The objectives of this study were to estimate genetic parameters for body weight (BW) and BW change (BWC) and genetic correlations of BW and BWC with diseases and genomic predicted transmitting abilities (PTA) of productive and conformation traits of Holsteins during the first 120 DIM. Daily BW data were from the Afiweigh cow body weighing system (SAE Afikim, Kibbutz Afikim, Israel), which records BW as a cow exits the milking parlor. Disease categories included metabolic diseases, ketosis, infectious diseases, mastitis, reproductive diseases, and other diseases. Edited data included 68,914 and 11,615 daily BW observations from 441 Pennsylvania State University and 72 Virginia Tech Holstein cows, respectively. Two-trait random regression models were used to estimate relationships between BW, BWC, and diseases at 25, 38, and 58 mo of age at calving. Fixed effects for BW were age at calving nested within lactation group, week of lactation, and herd date; random effects for BW included animal, permanent environment, and error. Fixed effects for disease were herd-year-season of calving and age at calving nested within lactation group; random effects for disease were animal, permanent environment (for mastitis only), and error. Correlations of PTA for BW and BWC with genomic PTA for productive and type traits were also estimated with data from 117 cows. Heritability estimates for daily BW ranged from 0.34 to 0.63 . Greater BW and less BWC were favorably correlated with ketosis, metabolic diseases, infectious diseases, and other diseases. The genetic correlation estimate between BW and ketosis was strongest at 60 DIM (-0.51), and genetic correlation estimates at 60 DIM with metabolic diseases $(-0.52)$, infectious diseases $(-0.81)$, and other diseases $(-0.48)$ followed the same trend as ketosis. The genetic correlation estimate between BWC and ketosis was strongest for the change from 5 to 20 DIM (0.70) and was similar for metabolic

Received April 21, 2009.

Accepted November 3, 2009.

${ }^{1}$ Corresponding author: erika.frigo@unimi.it diseases (0.37), infectious diseases (0.74), and other diseases (0.49). Correlations of BW and BWC with reproductive diseases tended to be in the reverse direction of those reported for ketosis. A larger PTA for BW was significantly correlated with smaller genomic PTA for milk yield, dairy form, rear udder height, and udder cleft. Predicted transmitting ability for BWC was negatively correlated with genomic PTA for protein percentage, strength, and hip width (ranging from -0.26 to -0.13 across lactation) and was positively correlated with dairy form, rear udder height, and udder cleft (ranging from 0.20 to 0.37 across lactation). Selection for reduced BW loss can be implemented with automated body weighing systems and may be successful in decreasing disease incidence in the early stages of lactation.

Key words: body weight, disease, genetic correlation

\section{INTRODUCTION}

Nutrient demands of lactation typically exceed dietary intake potential in the early postpartum period. This results in a state of negative energy balance (NEB), during which body reserves are mobilized (predominantly fat) to provide additional substrate for milk production (Berglund and Danell, 1987; Veerkamp, 1998). Negative energy balance is a natural transient condition. However, NEB may be associated with health problems when the difference between energy intake and expenditure is too large (Collard et al., 2000). The intense lipid mobilization that occurs as a result of severe NEB can lead to the development of fatty liver syndrome, ketosis, reduced intake, and displaced abomasum (Grummer, 1993). The heritability of BW is moderate, and BW may be a tool in genetic selection programs to improve energy balance (Veerkamp et al., 2000). Recently, different studies have used electronically recorded daily $\mathrm{BW}$ to describe genetic and phenotypic parameters for $\mathrm{BW}$ and $\mathrm{BW}$ change (BWC) at crucial points during lactation. Toshniwal et al. (2008) reported that electronically recorded daily BW is highly heritable, and genetic evaluations of daily BW and BWC across lactation could be used to select 
for less early-lactation BW loss. Moreover, associations between 21-d cycles in BW and the estrous cycle were reported by Van Straten et al. (2008). Phenotypic associations of BW with diseases in high-producing cows are known; the action of the immune system is depressed because of the metabolic stress of parturition and onset of lactation (Goff and Horst, 1997; Leslie et al., 2000), and, as a consequence, cows that lose a great amount of BW in early lactation are more likely to develop diseases (Goff and Horst, 1997).

Body weight is a dynamic trait that is influenced by the frame size of a cow, its feed intake, and its BCS. Change in BW is also influenced by the age of the animal. A first-calf heifer, for example, could lose BCS in early lactation but still gain BW because of an increase in frame size. In mature cows that are not growing, a change in $\mathrm{BW}$ will more closely reflect a change in the level of BCS. A loss in BW during early lactation is due primarily to loss of BCS because it is not expected that the frame size a cow will decline, and there is a strong genetic relationship between BW and BCS (Toshniwal et al., 2008). Thus, associations between BWC and health are likely due to changes in BCS, and the availability of automated systems makes daily BW an attractive tool to select indirectly for change in BCS profiles. A rapid loss of BCS after calving has been associated with a higher incidence of metabolic disorders, impaired fertility, and other health problems (Gearhart et al., 1990; Gillund et al., 2001). Significant genetic correlation estimates between BCS, clinical mastitis, and metabolic diseases have also been documented (Lassen et al., 2003; Dechow et al., 2004).

Direct estimates of the genetic relationship of $\mathrm{BW}$ and BWC with disease are not as widely available as genetic correlation estimates between BCS and disease, although heritability estimates are widely available for BW. Berry et al. (2003) estimated the genetic correlation between $\mathrm{BW}$ on several days during first lactation and various fertility measures, and showed that although genetically heavier cows are served sooner, they require more services and have a longer interval from first service to conception. In a later study, Berry et al. (2007) reported that more BWC in early lactation was significantly associated with greater SCS, but the effect was not strong; Brotherstone et al. (2007) reported a negative genetic association between BW at first calving and reproductive disorders, as well as unfavorable genetic relationships of high growth rate with foot diseases.

Genomic PTA increases the accuracy of genetic evaluations and may lead to increased genetic gain by shortening the generation interval (VanRaden et al., 2009). Such evaluations are particularly valuable for young bulls and cows with few or no progeny. Genetic progress will be better understood by associating functional trait data, such as BW, with genomic PTA in research populations. The objectives of this study were to estimate (co)variances for BW and BWC, and genetic correlations of BW and BWC with diseases and genomic PTA in US Holsteins during the first 120 DIM.

\section{MATERIALS AND METHODS}

\section{Data}

Daily BW was collected from 441 (68,914 records) and 72 (11,615 records) Holstein cows from the Pennsylvania State University (PSU) and Virginia Tech (VT) dairy herds, respectively. Daily BW was from the Afiweigh cow body weighing system, which records $\mathrm{BW}$ as a cow exits the milking parlor. The average BW from the morning and evening milkings were stored by AfiFarm herd management software (SAE Afikim, Kibbuts Afikim, Israel) at PSU, whereas both morning and evening milking BW were retained by AfiFarm in the VT herd. Morning and evening BW were averaged for VT to be uniform with PSU. Afiweigh was introduced at PSU in August 2001 and in July 2004 at VT. Data were collected from the date of installation through September 2008 for PSU and through March 2008 for VT. Only BW between calving and 120 DIM was considered because metabolic diseases occur in early lactation and because considering observations beyond 120 d may require a model with higher order polynomials for random effects with little gain in accuracy for genetic evaluations during the period of interest. Records for BW that were identical for more than $5 \mathrm{~d}$ for the same cow indicated a scale error and were eliminated (Toshniwal et al., 2008), and only animals with at least $2 \mathrm{BW}$ records during the first week of lactation were included in the analysis.

Diseases were recorded by herd managers at both universities; disease categories $(1=$ diseased, $0=$ not diseased) included metabolic diseases, ketosis, infectious diseases, mastitis, reproductive diseases, and other diseases. The diseases included in each category are reported in Table 1. Some diseases were analyzed in multiple disease categories; for example, ketosis was analyzed as a stand-alone trait and also was included in the metabolic disease category. Sire and dam identification was extracted from herd management software, and sire pedigrees were extracted from Animal Improvement Programs Laboratory sire evaluation files.

\section{Analysis}

Across the first $120 \mathrm{~d}$ of lactation, BW was analyzed with the following random regression model in ASREML (Gilmour et al., 2006): 
Table 1. Individual traits included in each disease category

\begin{tabular}{ll}
\hline Disease category & Individual trait \\
\hline Metabolic disease & Displaced abomasum, ketosis, abomasal impaction, bloated, fatty liver, clostridial enteritis, hypocalcemia, scours \\
Ketosis & Ketosis \\
Infectious disease & Abscesses, Clostridium, endotoxemia, enteritis, eye infection, foot rot, infection, mastitis, coliform mastitis, \\
& toxic mastitis, metritis, pneumonia, retained placenta, tetanus \\
Mastitis & Mastitis, coliform mastitis, toxic mastitis \\
Reproductive disease & $\begin{array}{c}\text { Dystocia, cystic ovaries, metritis, prolapsed uterus, retained placenta, small ovaries, } \\
\text { torn uterus, torsion, uterine infusion, uveitis }\end{array}$ \\
Other disease & Sore feet, swollen feet, stress, hard breathing, coughing, injuries, hernia, intestinal gas \\
\hline
\end{tabular}

$$
\begin{aligned}
& y_{i j l m n q r s}=H D_{j}+W K_{s}+\sum_{c=1}^{2} b_{a l} \times a g e^{c}\left(L G_{l}\right) \\
& +\sum_{n=0}^{2} a_{i n} L+\sum_{q=0}^{2} p_{i q} L+a_{i m} L_{a g e}+p_{i r} L_{a g e}+e_{i j l m n q r s},
\end{aligned}
$$

where $y$ is the daily BW; $H D$ is the fixed effect of herd date $j ; W K$ is the fixed effect of week of lactation $s ; b_{a l}$ is a regression coefficient for age at calving nested in lactation group $l\left(L G_{i} ; l=1,2\right.$, or $\left.\geq 3\right)$; $a$ is a random regression coefficient for animal $i$ on a Legendre polynomial for DIM $(L)$ of order $n$ and a random regression coefficient on a first-order Legendre polynomial of age at calving $\left(L_{a g e}\right) ; p$ is a random regression coefficient for the permanent environmental effect of cow $i$ on $L$ of order $q$ and a random regression coefficient on $L_{a g e}$; and $e$ is the random residual. There were 4 animal effects and 4 permanent environmental effects for BW (intercept plus linear and quadratic effects for DIM and linear effects for age at calving). The order of $L$ was determined by selecting and minimizing the Akaike and Bayesian information criteria, which were in agreement. The model had 4 residual structures corresponding to the following weeks of lactation: 1 to 4,5 to 8,9 to 13 , and 14 to 17 . The model failed to converge when higher order polynomials for DIM and age at calving were fit both for animal and permanent environmental effects.

Six different 2-trait models were used to estimate the relationship between BW and various diseases. The effects for BW were as described above. Fixed effects for disease were herd-year-season of calving and age at calving nested within lactation group. Random effects for the disease traits were animal and permanent environment (for mastitis only).

The matrix $\mathbf{G}$ was a $13 \times 13$ (co)variance matrix for DIM in 10-d increments plus disease and was calculated with the covariance function $\mathbf{G}=\boldsymbol{\Phi}^{\mathrm{T}} \mathbf{C} \boldsymbol{\Phi}$ (Kirkpatrick et al., 1990), where $\boldsymbol{\Phi}$ is a $13 \times 5$ matrix relating $L$, $L_{\text {age }}$, and disease with $\mathbf{C}$, and $\mathbf{C}$ is a $5 \times 5$ matrix containing the covariance components for the additive genetic random regression coefficients. The matrix $\mathbf{\Phi}$ was constructed for 25,38 , and 58 mo of age at calving, which corresponded to the average age at calving for lactations 1,2 , and $\geq 3$.

Likewise, a (co)variance matrix was computed for the permanent environmental effect $(\mathbf{P E})$. The residual covariance matrix $(\mathbf{R})$ was a $4 \times 4$ identity matrix multiplied by the residual variance components for each lactation period defined previously. The phenotypic covariance matrix $(\mathbf{P})$ was the sum of the additive genetic, permanent environmental, and residual covariance matrices $(\mathbf{P}=\mathbf{G}+\mathbf{P E}+\mathbf{R})$.

To estimate heritability for BWC, genetic variance for BWC was estimated as described by Toshniwal et al. (2008):

$$
\delta_{5-\mathrm{DIM}}^{2}=\delta_{5}^{2}+\delta_{\mathrm{DIM}}^{2}-2 \times \delta_{5, \mathrm{DIM}},
$$

where $\delta_{5}^{2}$ is the genetic variance estimate on DIM 5 ; $\delta_{\text {DIM }}^{2}$ is the genetic variance estimate at DIM 10 through 120 in 10-d increments; and $\delta_{5, \text { DIM }}$ is the genetic covariance between DIM 5 and DIM 10 through 120 in 10-d increments. Phenotypic and permanent environmental variances were estimated using the same procedures.

The heritability $\left(h^{2}\right)$ of BW and BWC for different DIM and the genetic correlations $(r g)$ between BW, BWC, and diseases at different DIM were computed as

$$
\begin{gathered}
h_{i}^{2}=\frac{g_{i, i}}{p_{i, i}}, \text { and } \\
r g_{i, k}=\frac{g_{j, k}}{\sqrt{g_{j, j} \times g_{k, k}}},
\end{gathered}
$$

where $g_{i, i}$ and $p_{i, i}$ are the diagonal elements of matrices $\mathbf{G}$ and $\mathbf{P}$ corresponding to the genetic and phenotypic variances for BW and BWC at different DIM, and $g_{j, k}$ is the element of the $\mathbf{G}$ matrix corresponding to the 
genetic covariance between BW, BWC, and diseases at different DIM.

The standard errors for heritability and genetic correlations were calculated with the methodology proposed by Fischer et al. (2004). The formulas used to estimate the variance of the heritability and the variance of the genetic correlation estimates were given by the following equations:

$$
\begin{gathered}
\operatorname{var}\left(h_{i}^{2}\right)=\operatorname{var}\left(\frac{g_{i, i}}{p_{i, i}}\right) \\
=\left(h^{2}\right)^{2}\left[\frac{v g_{i, i}}{\left(g_{i, i}\right)^{2}}+\frac{v p_{i, i}}{\left(p_{i, i}\right)^{2}}-2 \times \frac{\operatorname{cov}\left(g_{i, i}, p_{i, i}\right)}{g_{i, i} \times p_{i, i}}\right], \text { and } \\
=r g^{2}\left[\begin{array}{l}
\frac{\operatorname{var}(r g)=\operatorname{var}\left(\frac{g_{j, k}}{\sqrt{g_{j, j} \times g_{k, k}}}\right)}{4\left(g_{j, j}\right)^{2}}+\frac{\operatorname{var}\left(g_{k, k}\right)}{4\left(g_{k, k}\right)^{2}}+\frac{\operatorname{var}\left(g_{j, k}\right)}{\left(g_{j, j}\right)^{2}} \times g_{k, k} \\
+\frac{2 \operatorname{cov}\left(g_{j, j}\right) \times g_{j, k}}{2\left(g_{j, j}\right) \times\left(g_{j, k}\right)} \\
-\frac{2 \operatorname{cov}\left(g_{j, k}\right) \times g_{k, k}}{2\left(g_{j, k}\right) \times\left(g_{k, k}\right)}
\end{array}\right],
\end{gathered}
$$

where $g_{i, i}, p_{i, i}, v g_{i, i}$, and $v p_{i, i}$ were the diagonal elements of $\mathbf{G}, \mathbf{P}, \mathbf{V G}$, and $\mathbf{V P}$, respectively; $\mathbf{V G}$ and $\mathbf{V P}$ were variance matrices of $\mathbf{G}$ and $\mathbf{P}$.

The random regression solutions were used to estimate PTA for BW from DIM 0 to 120 in 10-d increments. These PTA, in addition to PTA for BW at 5 DIM, were then used to derive PTA for BWC from DIM 5 to DIM 10 through 120 in 10-d increments. The BW PTA were correlated to genomic PTA (VanRaden et al., 2009) that were available for 110 PSU and 7 VT cows, using the CORR procedure of SAS (SAS Institute, 2000). The average reliability of the genomic PTA $\left(R_{G}\right)$ and average reliability of the BW PTA $\left(R_{B W}\right)$ used to estimate the correlations was calculated. Correlations between genomic PTA and BW PTA were then deregressed by dividing by the square root of $R_{G} \times R_{B W}$.

\section{RESULTS AND DISCUSSION}

The average daily BW was $609.8 \mathrm{~kg}$ for PSU and 565.7 $\mathrm{kg}$ for VT, with standard deviations equal to 87.1 and $62.7 \mathrm{~kg}$ for PSU and VT, respectively. It was reported previously that cows at PSU had greater recorded BW than cows at VT both within and across lactation, but that scales at the respective universities had not been cross-validated (Toshniwal et al., 2008). Means of daily BW, with their standard deviations for each lactation group (1, 2, and $\geq 3)$, at $1,4,8,13$, and $17 \mathrm{wk}$ of lactation are presented in Table 2 . Cows with 3 or more lactations lost more BW within the first 4 wk of lactation. The frequencies of each disease category are presented in Table 3. Disease frequencies ranged from 4.0 to $47.2 \%$. Of the diseases analyzed, the infectious diseases had the highest frequencies for both herds (39 and $47.2 \%$ for PSU and VT, respectively), whereas the lowest frequency was represented by ketosis for PSU (5.8\%) and by other diseases for VT (no observations). Disease frequencies were greater than many published estimates of the frequency of cow diseases (Lin et al., 1989; Dechow et al., 2004) and likely indicate more careful disease recording in the research herds.

\section{Variance Components}

Heritability estimates for BW at different stages of lactation and at different ages are reported in Table 4. Results were from the BW and ketosis model, but were almost identical for all 6 random regression models. Heritability for BW ranged from 0.54 (10 DIM) to 0.64 (70 DIM), from 0.36 (120 DIM) to 0.49 (70 DIM), and

\begin{tabular}{|c|c|c|c|c|c|c|}
\hline \multirow[b]{3}{*}{ BW (kg) } & \multicolumn{6}{|c|}{ Lactations } \\
\hline & \multicolumn{2}{|c|}{1} & \multicolumn{2}{|c|}{2} & \multicolumn{2}{|c|}{$\geq 3$} \\
\hline & Mean & $\mathrm{SD}$ & Mean & $\mathrm{SD}$ & Mean & $\mathrm{SD}$ \\
\hline At 7 DIM & 562.57 & 65.3 & 656.80 & 71.1 & 718.53 & 78.5 \\
\hline At 28 DIM & 529.87 & 57.7 & 619.37 & 64.1 & 675.24 & 70.8 \\
\hline At 56 DIM & 534.86 & 57.6 & 621.71 & 60.5 & 673.65 & 64.4 \\
\hline At 91 DIM & 553.47 & 55.7 & 638.52 & 61.7 & 688.60 & 62.8 \\
\hline At 119 DIM & 562.62 & 56.8 & 646.33 & 61.9 & 692.17 & 66.3 \\
\hline
\end{tabular}
from 0.34 (60 DIM) to 0.40 (10 DIM) at 25,38 , and 58 mo of age at calving, respectively. Heritability of BWC

Table 2. Means and standard deviations of daily BW for each lactation group at 7, 28, 56, 91, and 119 DIM 
Table 3. Frequency (\%) of disease incidence in the Pennsylvania State University (PSU) and Virginia Tech (VT) dairy herds

\begin{tabular}{lcc}
\hline Disease category & PSU & VT \\
\hline Metabolic diseases & 18.6 & 33.3 \\
Ketosis & 5.8 & 19.4 \\
Infectious diseases & 39 & 47.2 \\
Mastitis & 16.3 & 30.5 \\
Reproductive diseases & 11 & 4.0 \\
Other diseases & 20.6 & 0.0 \\
\hline
\end{tabular}

from DIM 5 to different stages of lactation is reported in Table 5 and ranged from 0.01 to 0.30 . The heritability estimate of BWC was identical at all ages at calving because attempts to fit random interactions between age and stage of lactation failed to converge.

Heritability estimates across the entire lactation for different ages at calving are plotted in Figure 1. Heritability for BW and BWC estimates from the present study are within the range of estimates from other studies (Berry et al., 2002; Toshniwal et al., 2008). In the current study, the heritability for BW at 25 mo of age at calving was greater than that found at 58 mo of age at calving. The genetic variance at 58 mo of age at calving was larger than those estimated for 25 and 38 mo of age at calving. Heritability estimates were smaller at 58 mo of age because of permanent environmental variance estimates that were more than 2 times higher than that at 25 mo of age. This may indicate that environmental effects accumulate with increasing age of the animal.

\section{Correlations Between BW and Diseases}

Heritability estimates for disease and genetic correlation estimates of BW at 25 mo of age at calving with various diseases are reported in Table 6. Correlations of BW with disease were similar across all ages, so only those for BW at 25 mo of age are reported. Genetic correlation estimates of $\mathrm{BW}$ with ketosis, BW with metabolic disease, BW with infectious disease, and BW with other disease categories were similar across lactation; genetic correlation estimates of $\mathrm{BW}$ at 60 DIM with ketosis $(-0.51)$, metabolic diseases $(-0.52)$, infectious diseases $(-0.81)$, and other diseases $(-0.48)$

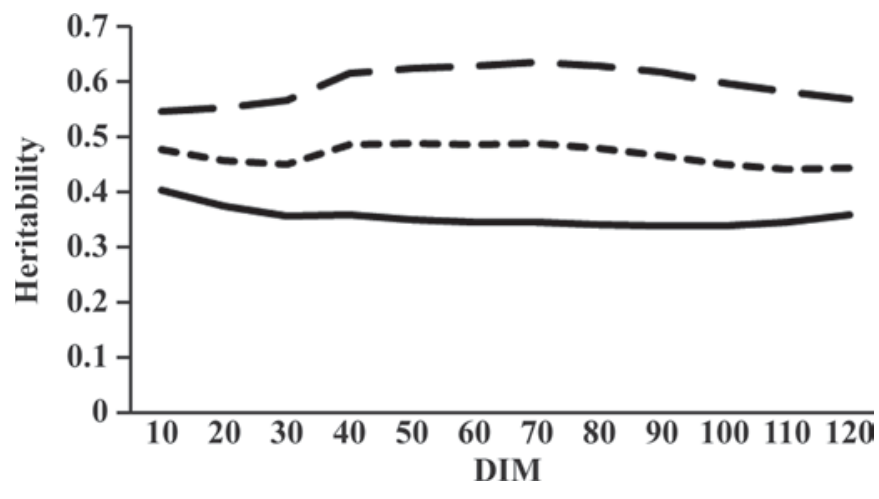

Figure 1. Heritability of BW across lactation at 25 mo (long dashed line), 38 mo (short dashed line), and 58 mo (black line) of age at calving.

were stronger than correlations for BW at 10 or 120 DIM. Heritability estimates were larger for ketosis and metabolic diseases ( 0.11 and 0.13 , respectively) than for other diseases, and standard errors for genetic correlation estimates involving ketosis and metabolic diseases were smaller.

Genetic correlation estimates of BW with reproductive diseases were different from those estimated between $\mathrm{BW}$ and the other diseases. The genetic correlation between BW and reproductive diseases was strongest at 10 DIM (-0.60) and was near zero at 120 DIM (-0.04). The pattern of genetic correlation estimates of BW and mastitis was also different from that of $\mathrm{BW}$ with other disease categories, steadily decreasing from 0.15 at 10 DIM to -0.71 at 120 DIM. The phenotypic correlation estimates of BW with diseases (Table 7 ) were in the same direction as genetic estimates at the same stage of lactation for all the disease categories.

Patterns of genetic correlation for BW with ketosis, metabolic diseases, infectious diseases, and other diseases suggest a strong relationship between BW and health traits. The moderate to strong correlations between BW and diseases suggested that cows genetically inclined to have a greater BW in the early lactation would be less inclined to have diseases, particularly ketosis, metabolic diseases, and infectious diseases. A previous study on the same population estimated a genetic correlation between daily BW and BCS of 0.60

Table 4. Heritability estimates $( \pm \mathrm{SE})$ and genetic standard deviations $\left(\mathrm{SD}_{\mathrm{a}}\right)$ for daily $\mathrm{BW}$ at 25,38 , and 58 mo of age at calving at 10,60 , and 120 DIM

\begin{tabular}{|c|c|c|c|c|c|c|}
\hline DIM & \multicolumn{2}{|c|}{25 mo of age at calving } & \multicolumn{2}{|c|}{38 mo of age at calving } & \multicolumn{2}{|c|}{58 mo of age at calving } \\
\hline 10 & $0.54 \pm 0.015$ & 54.83 & $0.47 \pm 0.042$ & 45.09 & $0.40 \pm 0.070$ & 59.85 \\
\hline 120 & $0.57 \pm 0.009$ & 54.91 & $0.44 \pm 0.043$ & 45.50 & $0.36 \pm 0.055$ & 60.49 \\
\hline
\end{tabular}


Table 5. Heritability estimates $( \pm \mathrm{SE})$ and genetic standard deviations $\left(\mathrm{SD}_{\mathrm{a}}\right)$ for $\mathrm{BW}$ change (BWC) from 5 to 10,5 to 60 , and 5 to 120 DIM

\begin{tabular}{lcc}
\hline BWC & $\mathrm{h}^{2}$ & $\mathrm{SD}_{\mathrm{a}}$ \\
\hline 5 to 10 DIM & $0.01 \pm 0.004$ & 4.71 \\
5 to 60 DIM & $0.37 \pm 0.007$ & 30.53 \\
5 to 120 DIM & $0.30 \pm 0.007$ & 14.71 \\
\hline
\end{tabular}

and indicated a tendency for BCS to be more highly correlated with daily BW in early and late lactation than with daily BW in midlactation (Toshniwal et al., 2008).

Significant genetic correlation estimates between BCS and diseases have been documented (Lassen et al., 2003; Dechow et al., 2004); cows with high genetic merit for BCS are genetically less disposed to disease, whereas cows that have low genetic merit for BCS are more prone to metabolic problems in particular. Studies also indicated that cows with lower BCS have lower conception rates and decreased efficiency of heat detection compared with cows that are gaining BW and that have higher BCS (Pryce et al., 2001). Results of the current study are in agreement with those of others suggesting that heavier cows are more inclined to have higher BCS and therefore less disease; Brotherstone et al. (2007) also reported that cows that were heavier at calving suffered fewer reproductive problems during the first lactation. Nevertheless, results of the current study are in contrast with those of Hansen et al. (1999), who concluded that selection for a larger frame size in Holstein cows may not be economically justifiable and that cows selected for a larger frame size generally had more health problems and shorter productive lives. Sire selection was determined by body dimension in that study (stature, body depth, strength) and although cows in the large cow line weighed more, they may not have had higher BCS. Additionally, cows with large frames have more total body fat than smaller framed cows with equal BCS (Banos et al., 2006); therefore, a large-framed cow with an equivalent change in BCS as a small-framed cow will be mobilizing more BCS and will likely be at greater risk for the development of metabolic diseases.

\section{Correlations Between BWC and Diseases}

Genetic correlation estimates of BWC with disease are reported in Table 8 . The phenotypic correlation estimates of BWC with disease (not shown) presented the same tendency as the genetic correlations at the same stage of lactation for all the disease categories.

Genetic correlations of BWC with disease were similar for ketosis, metabolic diseases, mastitis, infectious diseases, and other diseases categories and indicated that more BW loss was associated with more frequent disease occurrence. The genetic correlation estimate between BWC and ketosis was strongest for the change from 5 to 20 DIM (0.70) and was positive from 5 to 20 DIM for metabolic diseases (0.37), infectious diseases (0.74), and other diseases (0.49). The genetic correlations between BWC from 5 to 120 DIM and these diseases were smaller in magnitude and in the opposite direction (for ketosis, metabolic diseases, and infectious diseases).

Genetic correlation patterns of BWC with ketosis, mastitis, metabolic diseases, infectious diseases, and other disease categories indicated a strong relationship between BWC and health traits. Cows genetically inclined to have a greater BW loss in early lactation were more inclined to have diseases, particularly ketosis, mastitis, metabolic diseases, and infectious diseases. During early lactation, the ability of a cow to maintain the balance between lactation demands and nutrient utilization is compromised, and this can adversely affect well-being. Extreme negative energy and nutritional imbalances predispose the cow to lose BW and subsequently develop metabolic and health problems that can affect milk production during the entire lactation (Gröhn et al., 1995). However, it is not clear whether BW loss predisposes cows to disease or disease predisposes cows to BW loss. Disease has been demonstrated to result in more lactation persistency in this population (Appuhamy et al., 2007) and in commercial herds (Appuhamy et al., 2009). This suggests that disease alters intake, yield, energy balance, and, subsequently, BWC.

A very different pattern of correlation between BWC and reproductive diseases was observed. The range of

Table 6. Heritability estimates $( \pm \mathrm{SE})$ of diseases and genetic correlation estimates of diseases with $\mathrm{BW}$ at 10 DIM (BW10), 60 DIM (BW60), and 120 DIM (BW120) at 25 mo of age at calving

\begin{tabular}{lcrrr}
\hline Disease trait & Disease $^{2}$ & \multicolumn{1}{c}{ BW10 } & BW60 & \multicolumn{1}{c}{ BW120 } \\
\hline Metabolic diseases & $0.13 \pm 0.038$ & $-0.37 \pm 0.141$ & $-0.52 \pm 0.139$ & $0.01 \pm 0.100$ \\
Ketosis & $0.11 \pm 0.035$ & $-0.23 \pm 0.135$ & $-0.51 \pm 0.145$ & $0.02 \pm 0.211$ \\
Infectious diseases & $0.03 \pm 0.033$ & $-0.44 \pm 0.476$ & $-0.81 \pm 0.526$ & $-0.05 \pm 0.284$ \\
Mastitis & $0.01 \pm 0.046$ & $0.15 \pm 0.547$ & $-0.23 \pm 0.832$ & $-0.71 \pm 1.322$ \\
Reproductive diseases & $0.06 \pm 0.038$ & $-0.60 \pm 0.220$ & $-0.06 \pm 0.365$ & $-0.04 \pm 0.087$ \\
Other diseases & $0.06 \pm 0.035$ & $-0.21 \pm 0.140$ & $-0.48 \pm 0.224$ & $-0.16 \pm 0.204$ \\
\hline
\end{tabular}


Table 7. Phenotypic correlation estimates between diseases and BW at 10 DIM (BW10), 60 DIM (BW60), and 120 DIM (BW120) at 25 mo of age at calving

\begin{tabular}{lcrr}
\hline Disease trait & BW10 & BW60 & \multicolumn{1}{c}{ BW120 } \\
\hline Metabolic diseases & $-0.21 \pm 0.142$ & $-0.37 \pm 0.140$ & $0.01 \pm 0.145$ \\
Ketosis & $-0.12 \pm 0.130$ & $-0.40 \pm 0.142$ & $0.01 \pm 0.409$ \\
Infectious diseases & $-0.22 \pm 0.492$ & $-0.53 \pm 0.528$ & $-0.03 \pm 0.292$ \\
Mastitis & $0.04 \pm 0.680$ & $-0.12 \pm 0.770$ & $-0.34 \pm 1.314$ \\
Reproductive diseases & $-0.44 \pm 0.232$ & $-0.08 \pm 0.217$ & $-0.03 \pm 0.204$ \\
Other diseases & $-0.10 \pm 0.143$ & $-0.31 \pm 0.223$ & $-0.12 \pm 0.202$ \\
\hline
\end{tabular}

the genetic correlations for BWC with reproductive diseases was from -0.81 (from 5 to 10 DIM) to -0.87 (from 5 to 120 DIM). Collard et al. (2000) reported that cows with reproductive disorders had lower milk yield and, subsequently, reached a state of positive energy balance $14 \mathrm{~d}$ faster than cows without reproductive diseases, and this depressed milk production may reduce energy needs and potentially allow cows to reach positive energy balance more rapidly. The genetic correlations of BW and BWC with reproductive diseases found in this study may indicate that cows genetically inclined to have reproductive diseases lose less BW in early lactation in some instances because of a reduction in energy requirements to support lactation. These genetic correlation estimates were based on a relatively small population and warrant further investigation to determine if they were the result of sampling error. Loss of BCS resulting from NEB is genetically associated with poorer fertility (Dechow et al., 2002). However, the genetic correlation between retained placenta and fertility traits was reported to be low (Heringstad et al., 2009), and reproductive diseases may have a relationship with BWC that is different from the relationship between BWC and fertility. This could highlight a potential challenge when selecting for reduced BW loss in early lactation. Such a selection strategy would likely be associated with less ketosis and metabolic disease, but could result in indirect selection for more reproductive diseases. Reproductive disease status may need to be included in the analysis of BW to prevent such an unintended result.

The genetic correlations between BWC and mastitis at some points across lactation (from 5 to 90 DIM to
5 to 120 DIM) were out of range, indicating that the model did not converge to a positive definite solution (Gilmour and Thompson, 2003). Out-of-range values were associated with high standard errors for the mastitis model (from 0.89 to 2.42 ), which may have resulted from the small number of observations included in the analysis. The low heritability estimates for mastitis also contributed to large standard errors. Nevertheless, results for mastitis from the current study agree with those of Banos et al. (2006); unfavorable body energy status may lead to mastitis incidence, thereby compromising udder health.

\section{Correlations of PTA for BW and BWC with Genomic PTA}

Correlations of PTA for BW and BWC with genomic PTA for production and type traits at 25 mo of age at calving are reported in Table 9 after adjustment for reliability. Correlations of PTA for BW and BWC with genomic PTA were similar at other ages at calving. The reliability estimated for BW PTA ranged from 61 (120 DIM) to $69 \%$ (60 DIM). The reliability estimates for BWC PTA ranged from $59 \%$ for 5 to 120 DIM to $82 \%$ for 5 to 60 DIM.

A higher PTA for BW was significantly correlated with lower genomic PTA for milk yield, dairy form, and rear udder height. Higher PTA for BW was positively correlated with fat yield, protein percentage, strength, and hip width (ranging from 0.15 to 0.61 across lactation). Higher PTA for BWC was correlated with lower protein percentage, fat yield, strength, and hip width (ranging from -0.14 to -0.46 across lacta-

Table 8. Genetic correlation estimates $( \pm \mathrm{SE})$ between $\mathrm{BW}$ change $(\mathrm{BWC})^{1}$ and diseases at 25 mo of age at calving

\begin{tabular}{lrrrr}
\hline Disease trait & BW5 to 10 & BW5 to 20 & BW5 to 60 & \multicolumn{1}{c}{ BW5 to 120 } \\
\hline Metabolic diseases & $0.29 \pm 0.142$ & $0.37 \pm 0.136$ & $0.27 \pm 0.143$ & $-0.44 \pm 0.168$ \\
Ketosis & $0.64 \pm 0.143$ & $0.70 \pm 0.152$ & $0.62 \pm 0.117$ & $-0.29 \pm 0.213$ \\
Infectious diseases & $0.64 \pm 0.457$ & $0.74 \pm 0.487$ & $0.62 \pm 0.450$ & $-0.37 \pm 0.213$ \\
Mastitis & $0.62 \pm 1.080$ & $0.47 \pm 0.899$ & $0.65 \pm 1.117$ & $1.50 \pm 2.424$ \\
Reproductive diseases & $-0.81 \pm 0.246$ & $-0.75 \pm 0.235$ & $-0.82 \pm 0.252$ & $-0.87 \pm 0.323$ \\
Other diseases & $0.47 \pm 0.210$ & $0.49 \pm 0.205$ & $0.47 \pm 0.212$ & $0.05 \pm 0.231$ \\
\hline
\end{tabular}

${ }^{1} \mathrm{BW} 5$ to 10 , BW5 to 20 , BW5 to 60 , BW5 to $120=$ change in BW between the respective DIM. 
Table 9. Correlations of PTA for BW and BW change (BWC) with genomic PTA for production and type traits at 25 mo of age at calving

\begin{tabular}{lcccc}
\hline Trait $^{1}$ & BW60 & BW120 & BWC5 to 60 & BWC5 to 120 \\
\hline Milk (kg) & $-0.655^{* * *}$ & $-0.830^{* * *}$ & 0.020 & 0.174 \\
Fat (kg) & $0.530^{*}$ & $0.372^{*}$ & $-0.461^{* *}$ & -0.240 \\
Protein (\%) & $0.560^{* *}$ & $0.615^{* * *}$ & $-0.186^{\dagger}$ & $-0.264^{\dagger}$ \\
Stature & 0.032 & 0.057 & 0.021 & -0.040 \\
Strength & $0.235^{*}$ & $0.227^{*}$ & $-0.260^{*}$ & $-0.203^{*}$ \\
Body depth & 0.126 & 0.151 & 0.029 & -0.053 \\
Dairy form & $-0.535^{*}$ & $-0.453^{*}$ & $0.372^{\dagger}$ & $0.303^{* *}$ \\
Hip width & $0.155^{\dagger}$ & $0.184^{\dagger}$ & $-0.136^{\dagger}$ & $-0.229^{*}$ \\
Rear udder height & $-0.486^{* *}$ & $-0.521^{*}$ & $0.249^{* *}$ & $0.334^{* * *}$ \\
Udder cleft & $-0.287^{* *}$ & -0.277 & $0.203^{*}$ & $0.289^{* *}$ \\
\hline
\end{tabular}

${ }^{1} \mathrm{BW} 60, \mathrm{BW} 120=\mathrm{BW}$ at 60 and $120 \mathrm{DIM}$, respectively; BWC5 to 60 , BWC5 to $120=$ change in BW between the respective DIM.

${ }^{\dagger} P<0.10 ;{ }^{*} P<0.05 ;{ }^{* *} P<0.01 ;{ }^{* * *} P<0.001$.

tion) and was positively correlated with dairy form, rear udder height, and udder cleft (ranging from 0.20 to 0.37 across lactation). All these correlations were consistent with expectations when variation in $\mathrm{BW}$ was highly correlated with BCS in this population. Higher BCS has been correlated with lower yield (Dechow et al., 2001), and lower dairy form (Dechow et al., 2003), lower rear udders, and weaker udder clefts (Dal Zotto et al., 2007). The lack of significant associations with stature and body depth also indicates that BW differences in this population are primarily due to differences in BCS.

Cows with greater genomic PTA or dairy form were genetically inclined to lose more BW in early lactation. This result corresponds to reports that BCS and dairy form (or angularity) are highly correlated (Dechow et al., 2003; Dal Zotto et al., 2007) and that cows genetically inclined to have higher BCS lose less body condition in early lactation (Dechow et al., 2002). Cows genetically inclined to have a lower dairy form appeared to maintain more BW in early lactation and were likely have a less severe NEB, resulting in less ketosis, metabolic disease, and infectious disease. Correlations of genomic PTA for milk yield with BWC indicate that selection for yield may result in more BW loss during the first $120 \mathrm{~d}$ of lactation, which also corresponds to observations by Dechow et al. (2002) that selection for milk yield increases early-lactation BCS loss.

\section{CONCLUSIONS}

Body weight is a moderately heritable trait, and significant genetic relationships of BW and BWC with ketosis, metabolic diseases, and infectious diseases suggest that selection for BW traits could limit unfavorable changes in cow health when selecting for higher yield. Installing automated cow weighing systems in progeny test herds could facilitate genetic evalua- tions of daily BW and BWC across lactations. High heritability estimates suggest that daily measurements from a subset of progeny test daughters of a bull would help identify sires whose daughters lose less BW during early lactation with reasonable accuracy. Daily BW from early lactation are the most critical and should be the primary focus because that is when the majority of metabolic disease occurs; however, BW in later lactation may have important relationships with fertility or health in the subsequent lactation and should be investigated more fully. Associations of BW and BWC PTA with genomic PTA also indicate that selection for less dairy form will help limit early-lactation BW loss.

\section{ACKNOWLEDGMENTS}

Genomic PTA were provided through USDA Cooperative State Research, Education, and Extension Service National Research Initiative Competitive Grant 200704216. Participation of the first author was supported by funds from the Department of Veterinary Sciences and Technologies for Food Safety, University of Milan, Milan, Italy. Appreciation is also expressed to the dairy herd managers for disease recordings.

\section{REFERENCES}

Appuhamy, J. A. D. R. N., B. G. Cassell, and J. B. Cole. 2009. Phenotypic and genetic relationships of common health disorders with milk and fat yield persistencies from producer-recorded health data and test-day yields. J. Dairy Sci. 92:1785-1795.

Appuhamy, J. A. D. R. N., B. G. Cassell, C. D. Dechow, and J. B. Cole. 2007. Phenotypic relationships of common health disorders in dairy cows to lactation persistency estimated from daily milk weights. J. Dairy Sci. 90:4424-4434.

Banos, G., M. P. Coffey, E. Wall, and S. Brotherstone. 2006. Genetic relationship between first-lactation body energy and later-life udder health in dairy cattle. J. Dairy Sci. 89:2222-2232.

Berglund, B., and B. Danell. 1987. Live weight changes, feed consumption, milk-yield and energy-balance in dairy-cattle during the 1st period of lactation. Acta Agric. Scand. A 37:495-509. 
Berry, D. P., F. Buckley, P. Dillon, R. D. Evans, M. Rath, and R. F. Veerkamp. 2002. Genetic parameters for level and change of body condition score and body weight in dairy cows. J. Dairy Sci. 85:2030-2039.

Berry, D. P., F. Buckley, P. Dillon, R. D. Evans, M. Rath, and R. F. Veerkamp. 2003. Genetic relationships among body condition score, body weight, milk yield and fertility in dairy cows. J. Dairy Sci. 86:2193-2204.

Berry, D. P., J. M. Lee, K. A. Macdonald, C. R. Staples, K. Stafford, L. Matthews, and J. R. Roche. 2007. Associations among body condition score, body weight, somatic cell count and clinical mastitis in seasonally calving dairy cattle. J. Dairy Sci. 90:637648 .

Brotherstone, S., M. P. Coffey, and G. Banos. 2007. Genetic parameters in dairy cattle and associations between growth and health traits. J. Dairy Sci. 90:444-450.

Collard, B. L., P. J. Boettcher, J. C. M. Dekkers, D. Peticlerc, and L. R. Schaeffer. 2000. Relationships between energy balance and health traits of dairy cattle in early lactation. J. Dairy Sci. 83:2683-2690.

Dal Zotto, R., M. De Marchi, C. Dalvit, M. Cassandro, L. Gallo, P. Carnier, and G. Bittante. 2007. Heritabilities and genetic correlations of body condition score and calving interval with yield, somatic cell score, and linear type traits in Brown Swiss cattle. J. Dairy Sci. 90:5737-5743.

Dechow, C. D., G. W. Rogers, and J. S. Clay. 2001. Heritabilities and correlations among body condition scores, production traits, and reproductive performance. J. Dairy Sci. 84:266-275.

Dechow, C. D., G. W. Rogers, and J. S. Clay. 2002. Heritabilities and correlations among body condition score loss, body condition score, production and reproductive performance. J. Dairy Sci. 85:3062-3070.

Dechow, C. D., G. W. Rogers, L. Klei, and T. J. Lawlor. 2003 Heritabilities and correlations among body condition score, dairy form and selected linear type traits. J. Dairy Sci. 86:2236-2242.

Dechow, C. D., G. W. Rogers, U. Sander-Nielsen, L. Klei, T. J Lawlor, J. S. Clay, A. E. Freeman, G. Abdel-Azim, A. Kuck, and S. Schnell. 2004. Correlations among body condition scores from various sources, dairy form, and cow health from the United States and Denmark. J. Dairy Sci. 87:3526-3533.

Fischer, T. M., A. R. Gilmour, and J. H. J. van der Werf. 2004. Computing approximate standard errors for genetic parameters derived from random regression models fitted by average information REML. Genet. Sel. Evol. 36:363-369.

Gearhart, M. A., C. R. Curtis, H. N. Erb, R. D. Smith, C. J. Sniffen, L. E. Chase, and M. D. Cooper. 1990. Relationship of changes in condition score to cow health in Holsteins. J. Dairy Sci. 73:31323140.

Gillund, P., O. Reksen, Y. T. Gröhn, and K. Karlberg. 2001. Body condition related to ketosis and reproductive performance in Norwegian dairy cows. J. Dairy Sci. 84:1390-1396.

Gilmour, A. R., B. J. Gogel, B. R. Cullis, S. J. Welham, and R. Thompson. 2006. AS-REML User Guide. Release 1.0. VSN International Ltd., Hemel Hempstead, UK.

Gilmour, A. R., and R. Thompson. 2003. Options for estimating variance components in large mixed models. Pages 206-209 in
Proc. 15th Conf. Assoc. Advance. Anim. Breed. Genet., Melbourne, Australia. AAABG, Melbourne, Australia.

Goff, J. P., and R. L. Horst. 1997. Physiological changes at parturition and their relationship to metabolic disorders. J. Dairy Sci. 80:1260-1268.

Gröhn, Y. T., S. W. Eicker, and J. A. Hertl. 1995. The association between previous 305-day milk yield and diseases in New York state dairy cows. J. Dairy Sci. 78:1693-1702.

Grummer, R. R. 1993. Etiology of lipid-related metabolic disorders in periparturient dairy cows. J. Dairy Sci. 76:3882-3896.

Hansen, L. B., J. B. Cole, G. D. Marx, and A. J. Seykora. 1999. Productive life and reasons for disposal of Holstein cows selected for large versus small body size. J. Dairy Sci. 82:795-801.

Heringstad, B., X.-L. Wu, and D. Gianola. 2009. Inferring relationships between health and fertility in Norwegian Red cows using recursive models. J. Dairy Sci. 92:1778-1784.

Kirkpatrick, M., D. Lofsvold, and M. Bulmer. 1990. Analysis of the inheritance, selection and evolution of growth trajectories. Genetics 124:979-993.

Lassen, J., M. Hansen, M. K. Sørensen, G. P. Aamand, L. G. Christensen, and P. Madsen. 2003. Genetic relationship between body condition score, dairy character, mastitis, and diseases other than mastitis in first-parity Danish Holstein cows. J. Dairy Sci. 86:3730-3735.

Leslie, K. E., T. F. Duffield, Y. H. Schukken, and S. J. LeBlanc. 2000. The influence of negative energy balance on udder health. Pages 25-32 in Proc. Natl. Mastitis Counc. Regional Mtg., Madison, WI. NMC, Madison, WI.

Lin, H. K., P. A. Oltenacu, L. D. Van Vleck, H. N. Erb, and R. D. Smith. 1989. Heritabilities of and genetic correlations among six health problems in Holstein cows. J. Dairy Sci. 72:180-186.

Pryce, J. E., M. P. Coffey, and G. Simm. 2001. The relationship between body condition score and reproductive performance. J. Dairy Sci. 84:1508-1515.

SAS Institute. 2000. SAS/STAT User's Guide. Version 8. SAS Inst. Inc., Cary, NC.

Toshniwal, J. K., C. D. Dechow, B. G. Cassel, J. A. D. R. N. Appuhamy, and G. A. Varga. 2008. Heritability of electronically recorded daily body weight and correlations with yield, dry matter intake, and body condition score. J. Dairy Sci. 91:3201-3210.

Van Straten, M., N. Y. Shpigel, and M. Friger. 2008. Analysis of daily body weight of high-producing dairy cows in the first one hundred twenty days of lactation and association with ovarian inactivity. J. Dairy Sci. 91:3353-3362.

VanRaden, P. M., C. P. Van Tassel, G. R. Wiggans, T. S. Sonstegard, R. D. Schnabel, J. F. Taylor, and F. S. Schenkel. 2009. Invited review: Reliability of genomic predictions for North American Holstein bulls. J. Dairy Sci. 92:16-24.

Veerkamp, R. F. 1998. Selection for economic efficiency of dairy cattle using information on live weight and feed intake: A review. J. Dairy Sci. 81:1109-1119.

Veerkamp, R. F., J. K. Oldenbroek, H. J. Van Der Gaast, and J. H. J. Van Der Werf. 2000. Genetic correlation between days until start of luteal activity and milk yield, energy balance, and live weights. J. Dairy Sci. 83:577-583. 